\title{
ANALISIS PERILAKU MEMBOLOS PADA PESERTA DIDIK MADRASAH ALIYAH RAUDHATUL ULUM KUBU RAYA
}

\author{
Hamdan Syakirin, Dr.Luhur Wicaksono, Dr.Indri Astuti \\ Program Studi Pendidikan Bimbingan dan Konseling FKIP Untan Pontianak \\ Email : hamdansyakirin91@gmail.com
}

\begin{abstract}
The title of this thesis is: analysis of truancy behavior in students of Madrasah Aliyah Raudhtul Ulum Kubu Raya. The general problems in this research are: how is the truancy behavior of students in Madrasah Aliyah Raudhatul Ulum Kubu Raya?;. whatever the sub problem: 1). What are the causes of students playing truant at Madrasah Aliyah Raudhatul Ulum Kubu Raya in 2020? 2). What are the activities of students who are truant at Madrasah Aliyah Raudhatul Ulum Kubu Raya in 2020? 3). How are the assistance efforts that have been made to solve the problem of truancy for students at Madrasah Aliyah Raudhatul Ulum Kubu Raya in 2020?

This study aims to obtain an objective description and information regarding truancy behavior in students of Madrasah Aliyah Raudhatul Ulum Kubu Raya. The approach used in this research is qualitative using descriptive method. The form of research used is a survey study (study studies). Data collection techniques in the form of observation, interviews, and documentation, the factors that cause students to skip school are: (1) often playing online games, (2) frequent condensation until morning (3) lack of supervision from parents. Efforts that can be made by BK teachers in dealing with this problem are (1) giving sanctions or punishments to students, and (2) giving stern warnings by not graduating or not going to class for those who are often truant.
\end{abstract}

\section{Keywords : Analysis Of Truant Behavior In Students}

\section{PENDAHULUAN}

Perilaku membolos sebenarnya bukan merupakan hal yang baru bagi banyak pelajar, sebab perilaku membolos itu sendiri telah ada sejak dulu. Tidak hanya di kota-kota besar saja Peserta Didik yang terlihat dari absensi kehadiran yang sering membolos, bahkan di daerah-daerah pun prilaku membolos sudah menjadi kegemaran. Di lihat dari ragam dan volumenya, Peserta didik yang sering bolos ini sangat bervariasi, ada yang bolos hampir setiap hari, ada yang bolos sekali-kali dan ada pula yang bolos hanya pada hari-hari tertentu saja, dengan bersifat negatif harus segera ditanggulangi. Salah satunya yaitu perilaku membolos.

Peserta Didik yang bolos sekolah ialah Peserta Didik yang dengan sengaja tidak masuk sekolah, karena tidak mau masuk dengan alasan- alasan tertentu termasuk di dalamnya adalah Peserta Didik yang selalu tidak hadir atau absen, baik pada hari-hari tertentu seperti hari-hari besar, atau pada hari-hari biasa, sering juga terlambat masuk kelas dan pulang sebelum waktunya serta Peserta Didik yang bolos pada mata pelajaran tertentu, misalnya Matematika, IPA, Bahasa Inggris dan sebagainya tergantung pada mata pelajaran yang kurang digemari.

Membolos dapat diartikan tidak masuk sekolah tanpa keterangan, tidak masuk ke sekolah selama beberapa hari, dari rumah berangkat tapi tidak sampai ke sekolah, dan meninggalkan sekolah pada saat jam pelajaran berlangsung. Gunarsa, (2012:79) Sering kali kita mendapati anakanak sekolah yang masih berseragam berkeliaran di luar sekolah pada jam sekolah. Jika zaman dahulu mungkin hanya sebatas anak laki-laki saja yang melakukan atau melestarikan kebudayaan ini 
namun akhir-akhir ini tidak jarang kita temukan anak perempuan yang membolos di jam sekolah sendiri dengan sesama teman atau membolos sendiri.

Perilaku demikian dapat di pengaruhi oleh lingkungan Seorang Peserta Didik dikatakan bolos sekolah adalah apabila ia pamit kepada orang tuanya atau walinya mau pergi kesekolah dan berpenampilan seolah-olah akan pergi ke sekolah tetapi tidak masuk sekolah, dari rumah pura-pura kesekolah, tetapi kenyataannya ia absen di Sekoah. Jika perilaku membolos seperti yang dikemukakan di atas dibiarkan dan tidak ditanggulangi dengan segera tentu akan membawa kerugian bagi anak-anak yang bersangkutan serta orang tuanya sendiri. Kerugian nyata yang akan dialami anak adalah menurunnya prestasi belajar karena jarang mengikuti pelajaran.

Pada akhirnya anak yang bersangkutan tidak naik kelas bahkan kemungkinan bisa berakibat fatal yaitu tidak dapat mengikuti pelajaran untuk seterusnya dan di nyatakan drop out atau dikeluarkan dari sekolahnya. Hal ini menjadi tanggung jawab pihak sekolah khususnya guru Bimbingan dan Konseling yang memiliki peran penting terhadap masalah sosial dan psikologis peserta didik di sekolah.

Menurut Gunarsa (dalam Kartika Sari 2017:7) "perilaku membolos secara umum dapat diartikan sebagai perilaku siswa yang tidak masuk sekolah dengan alasan yang tidak tepat atau ketidak hadiran Peserta Didik tanpa alasan yang jelas". Membolos yang dimaksud disini adalah Peserta Didik yang tidak masuk sekolah dalam tiga hari berturut-turut tanpa izin, membolos merupakan bentuk kenakalan Peserta Didik yang apa bila tidak segera ditangani maka dapat berpengaruh buruk untuk peserta didik yang bersangkutan.

Berdasarkan observasi yang dilakukan peneliti saat melaksanakan Praktek pengalaman lapangan di Madrasah Aliyah Raudhatul Ulum Kubu Raya, terdapat masalah terkait perilaku membolas peserta didik. Masalah yang sangat crusial adalah peserta didik yang sering tidak masuk sekolah dalam proses belajar mengajar berlangsung yang sangat mengganggu keberlangsungan proses belajar mengajar, oleh karena itu bisa menyebabkan peserta didik tidak bisa naik kelas, Selain itu peserta didik juga banyak ketinggalan mata pelajaran dan mengakibatkan nilainya rendah . Bagi peserta didik yang demikian itu akan berdampak buruk bagi sekolah dan juga untuk dirinya sendiri bisa menyebabkan tidak dapat menyerap materi yang disampaikan oleh guru mata pelajaran.

Berdasarkan latar belakang yang telah diuraikan di atas maka penulis memilih judul Analisis perilaku membolos peserta didik Madrasah Aliyah Raudhatul Ulum Kubu Raya Tahun 2020.

"Bagaimanakah perilaku membolos peserta didik di Madrasah Aliyah Raudhatul Ulum Kubu Raya?".

\section{METODE PENELITIAN}

Metode yang digunakan dalam penelitian ini adalah metode deskriptif dengan menggunakan pendekatan kualitatif. Menurut Sugiyono (2012:1) "penelitian kualitatif adalah penelitian yang digunakan untuk meneliti pada kondisi objek yang alamiah, (sebagai lawannya adalah eksperimen) dimana peneliti adalah sebagai instrument, kunci, teknik pengumpulan data dilakukan secara trianggulasi (gabungan), analisis data bersifat induktif, dan hasil penelitian kualitatif lebih menekankan makna dari pada generalisasi".

Menurut Yusuf, 2013: 334 penelitian kualitatif adalah untuk menemukan jawaban terhadap suatu fenomena atau pertanyaan melalui aplikasi prosedur ilmiah secara sistematis dengan menggunakan pendekatan kualitatif.

Dari pengertian di atas mengenai penelitian kualitatif dapat disimpulkan bahwa penelitian yang berupaya memahami, mengamati, dan menganbarkan keadaan seseorang maupun lingkungan sosialnya. 


\section{HASIL DAN PEMBAHASAN PENELITIAN \\ Hasil}

Sebelum melakukan penelitian di madrasah aliyah raudhatu ulum kubu raya,peneliti melakukan observasi di sekolah tersebut dari mulai lingkungan sekolahnya yang akan di jadikan tempat penelitian agar penelitian itu dapat berjalan dengan lancar.selama proses penelitian, peneliti mendahulukan kebutuhan kondisi subjek seperti memperhatikan kesiapan subjek agar penelitian ini dapat berjalan dengan lancar dan informasi yang di inginkan dapat sesuai.

Tabel 1 Hasil Analisis Perilaku Membolos Kepada Peserta Didik Madrasah Aliyah Raudhatul Ulum Kubu Raya.

\begin{tabular}{clcc}
\hline NO & \multicolumn{1}{c}{ Aspek yang di amati } & \multicolumn{2}{c}{ Jawaban } \\
\hline & & Ya & Tidak \\
1 & Sering membaca buku saat di rumah & & $\sqrt{ }$ \\
\hline 2 & Pernah datang keperpustakaan untuk membaca buku & $\sqrt{ }$ \\
\hline 3 & Nilai raport selalu meningkat & $\sqrt{ }$ & \\
\hline 4 & Sering bertanya saat sedang belajar & $\sqrt{ }$ \\
\hline 5 & Sering tidur saat sedang belajar & $\sqrt{ }$ \\
\hline 6 & Sering kesiangan pergi kesekolah & $\sqrt{ }$ \\
\hline 7 & Sering dihukum & $\sqrt{ }$ \\
\hline 8 & Selalu nongkrong untuk bermain & & $\sqrt{ }$ \\
\hline 9 & Sering diajak teman membolos & & \\
\hline 10 & Selalu mengerjakan soal &
\end{tabular}

\section{DATA YANG INGIN DI UNGKAP}

\section{KRITERIA PERILAKU} MEMBOLOS

\begin{tabular}{|c|c|c|}
\hline NO & PERTANYAAN & Jawaban \\
\hline 1 & $\begin{array}{l}\text { Apa yang anda lakaukan saat tidak masuk } \\
\text { sekolah? }\end{array}$ & $\begin{array}{l}\text { saat tidak masuk saya biasanya } \\
\text { ketiduran }\end{array}$ \\
\hline 2 & $\begin{array}{l}\text { Kegiatan apa saja yang anda lakukan saat } \\
\text { tidak sekolah? }\end{array}$ & biasanya tidur dan ber-main \\
\hline 3 & $\begin{array}{l}\text { Apakah anda mengerjakan tugas PR di } \\
\text { rumah? }\end{array}$ & Kadang Iya Kadang Tidak \\
\hline 4 & $\begin{array}{l}\text { Bagaimana anda menjaga lingkungan } \\
\text { sekolah agar tetap bersih? }\end{array}$ & $\begin{array}{l}\text { mengajak teman-teman menjaga } \\
\text { lingkungan dengan membuang } \\
\text { sampah pada tempatnya }\end{array}$ \\
\hline 5 & $\begin{array}{l}\text { Bagaimana sikap sosial anda dengan teman } \\
\text { sekelas? }\end{array}$ & $\begin{array}{l}\text { saling tolong menolong dan ingat- } \\
\text { mengingatkan }\end{array}$ \\
\hline 6 & $\begin{array}{l}\text { Bagaimana sikap sosial anda dengan teman } \\
\text { sekelas? }\end{array}$ & $\begin{array}{l}\text { saling tolong menolong dan ingat- } \\
\text { mengingatkan }\end{array}$ \\
\hline 7 & Apakah anda pernah ikut kerja bakti ? & iya pernah \\
\hline 8 & $\begin{array}{l}\text { Saat anda bolos sekolah apakah kamu } \\
\text { membantu orang tua mu? }\end{array}$ & Kadang iya \\
\hline 9 & Apakah anda malas untuk pergi kesekolah & $\begin{array}{l}\text { iya malas ditambah lagi susah } \\
\text { bangun pagi }\end{array}$ \\
\hline 10 & $\begin{array}{l}\text { Apakah anda pernah mengajak kawan anda } \\
\text { yang jarang masuk sekolah? }\end{array}$ & iya pernah \\
\hline
\end{tabular}




\section{Narasumber Subjek SR}

Hasil wawancara dengan SR pada tanggal 23 februari 2021 di ruang guru BK pukul 10.00 WIB menggunakan paparan dalam bentuk narasi sebagai berikut :

Hasi wawancara tahap awal yang dilakukan pada subjek SR adalah di mana dalam tahap awal subjek SR di panggil ke ruang guru Bimbingan Konseling untuk melakukan wawancara.

Sebelum di lakukan kegiatan wawancara terhadap subjek SR di awali dengan penjelasan tentang maksud dan tujuan dari wawancara yang di lakukan oleh peneliti. juga membuka kegiatan dengan cara membicarakan kegiatan yang ada di sekolah sehingga peserta didik ini merasa nyaman ketika berada di rauangan konseling tersebut. Hal ini di lakukan agar menghilangkan rasa takut yang ada pada peserta didik.

Pada tahap awal ini peneliti juga memberikan kesempatan kepada peserta didik untuk mengungkapkan permasalahannya tanpa merasa ragu-ragu, peneliti juga memberikan motivasi agar subjek SR selalu semangat. Dalam tahap awal peneliti dan subjek SR membentuk kontrak waktu dalam kegiatan wawancara sehingga kegiatan wawancara ini tidak melewati batas kontrak waktu yang telah di tentukan.

Subjek mengatakan bahawa semangat untuk belajar memang sangat menurun, waktunya banyak ia habiskan dengan bermain game online terlebih ditambah dengan adanya pelajaran yang kurang ia senangi. Teman dekat subjek ada dua orang yang sama-sama malas untuk belajar.

Setelah subjek SR menjelaskan permasalahannya peneliti memberikan motivasi yang baik dan menyemangati subjek SR tujuannya agar subjek tetap merasa nyaman untuk melanjutkan kegiatan wawancara ini.

\section{Pembahasan Penelitian}

Berdasarkan hasil wawancara
sebelumnya maka akan di lakukan
pembahasan dari hasil-hasil wawancara mulai
dari tahap awal, tahap pertengahan dan tahap
akhir analis.

1. Tahap awal
Pada tahap pembentukan ini hubungan yang baik di lakukan oleh peneliti dengan peserta didik sudah sangat baik di mana peneliti menyambut peserta didik yang datang keruang BK dengan ramah dan bersikap baik terhadap peserta didik. Dalam hal ini peneliti berusaha mengakrabkan diri kepada peserta didik sehingga peserta didik yang datang di panggil untuk melakukan wawancara tidak merasa takut. Hal ini sesuai dengan pernyataann Gladding (2015:175) "proses membangun hubungan baik sangat penting karena tahap pertama merupakan proses yang berkelanjutan sehingga menentkan keberhasilan proses wawancara selanjutnya". Pembentukan hubungan baik di awal kegiatan wawancara sangat penting karena jika pada tahap awal peneliti dapat menerima peserta didik dengan baik maka peserta didik akan dengan mudah terbuka dengan permasalaahnnya.

\section{Tahap pertengahan}

Pada tahap pertengahan ini peneliti memfokuskan pemberian bantuannya berupa saran atau nasehat. Pada tahap ini yang harus di lakukan seperti yang di ungkapkan Gladding (2015:224) dalam hal ini, peneliti membantu konseli melalui arahan yang tepat, mengubah persepsi, tanggapan multifokus, empati yang tepat, pengungkapan diri, mediasi, konfrontasi, kontrak dan latihan.

Guru pembimbing dapat memberikan saran dan nasehat dalam membantu permasalahan yang di hadapi peserta didik. Dalam tahap ini respon yang di tunjukkan oleh guru pembimbing sangat baik, namun masih ada beberapa peserta didik yang sulit untuk terbuka mengenai permaslahannya.

3. Tahap akhir

Tahap pengakhiran wawancara peserta didik yang telah melakukan kegiatan konseling dapat merubah perilaku kearah yang lebih baik di mana peserta didik dapat menyadari perilakunya. Hal ini sejalan dengan pernyataan Menurut Willis (2014:54) berdasarkan indikator keberhasilan konseling adalah :

a. Menurut kecemasan klien 
b. Mempunyai rencana hidup yang praktis, pragmatis, dan berguna

c. Harus ada perjanjian kapan rencananya akan di laksanakan sehingga pada pertemuan

Berikutnya konselor sudah bisa mengecek hasil pelaksanaan rencananya.

Menurut Willis (2014:54) mengenai evaluasi yaitu :

1. Klien menilai rencana perilaku yang akan di bauatnya

2. Klien menilai perubahan perilaku yang telah terjadi pada dirinya

3. Klien menilai proses dan tujuan konseling keberhasilan kegiatan konseling individual dalam tahap pengakhiran ini guru BK dapat menurunkan kecemasan yang ada pada peserta didik serta perubahan perilaku yang di miliki peserta didik.

\section{SIMPULAN DAN SARAN \\ Simpulan}

Berdasarkan hasil penelitian dan pembahasan yang telah peneliti lakukan, maka dapat di tarik kesimpulan umum bahwa analisis perilaku membolos pada peserta didik di madrasah aliyah raudhatul ulum kubu raya di sebabkan oleh factor intrinsic dan factor ekstrinsik. Sedangkan kesimpulan berdasarkan sub masalah penelitian ini, peneliti menyimpulkan sebagai berikut :

Penyebab peserta didik membolos dari faktor intrinsic

Penyebab dari faktor intrinsik

Subjek 1 HM Faktor intrinsik yang mempengaruhi subjek HM membolos yaitu :

Subjek HM memiliki aktivitas malam yakni bermain game online dengan teman yang lainnya. Subjek bermain game online hingga larut malam sehingga kekurangan waktu untuk tidur, akibatnya dia kesiangan saat akan pergi kesekolah.

\section{Subjek 2 SR}

Faktor intrinsik yang mempengaruhi subjek SR membolos yaitu :

Subjek SR biasanya selepas pulang mengaji dia belajar, namun karena sudah pergaulannya dia banyak memilih bermain game online ketimbang belajar, subjek tidak bisa menolak ajakan dari temannya ketika diajak bermain, hasilnya subjek lupa dengan belajarnya.Subjek $3 \mathrm{HR}$

Faktor intrinsik yang mempengaruhi subjek HM membolos yaitu :

Subjek HR yang tidak pernah belajar dirumah hanya melakukan rutinitas sekolah dan bermain, namun dari kedua rutinitas yang dilakukan subjek, subjek lebih cendrung sibuk bermain game online dengan temantemannya hingga larut malam. Biasanya subjek memulai nongkrong bermain game online dari jam 09.00 hingga jam 02 subuh. Akibatnya subjek kesiangan untuk pergi kesekolah.Penyebab peserta didik membolos dari faktor Ekstrinsik b. Penyebab dari factor ekstrinsik Subjek HMFaktor ekstrinsik yang mempengaruhi subjek HM membolos yaitu :Ketika subjek igin tidur awal, subjek selalu di tahan untuk pulang awal oleh temannya. Subjek SR Faktor ekstrinsik yang mempengaruhi subjek SR membolos yaitu : Subjek SR ketika ingin belajar malah di datangi oleh temannya untuk nongkrong. Sehingga subjek mengurungkan niatnya untuk belajar.

Subjek HR :Subjek yang berdekatan dengan tempat tongkrongan wifi atau biasa temantemannya bermain game online membuatnya lebih sibuk bermain ketimbang ingat untuk belajar, jarak rumah subjek yang sangat berdekatan membuatanya lupa untuk belajar. kegiatan peserta didik saat membolos :

Dari ketiga subjek ini, factor yang mendasari dari mereka membolos yakni factor lingkungan dan pergaulan mereka, karena lingkugan mereka yang berdekatan dengan tempat tongkrongan membuat mereka malas untuk belajar di tambah dengan pergaulan mereka dengan orang-orang yang sudah selesai sekolah. Dari ketiga peserta didik ini banyak menghabiskan waktu malamnya di tempat WI-FI, Terlebih dengan mereka yang sudah malas untuk mengaji.

Upaya yang sudah di lakukan guru BK untuk mengatasi peserta didik yang membolos

Guru BK bekerjasama dengan guru matapelajaran untuk memberikan sanksi kepada peserta didik yang membolos. Ketika peserta didik yang membolos ke esokan harinya sekolah, guru BK dan guru 
matapelajaran memberikan sanksi kepada mereka dengan membersihkan sampah yang ada didepan halaman sekolah.

Pernah juga guru BK mengancama akan mengeluarakan mereka dengan memanggil orangtua mereka, namun mereka masih saja, guru BK tidak bisa tegas untuk mengeluarkan mereka dari sekolah yang sering membolos di karenkan melihat mereka yang sudah kelas XII yang mana sebentar lagi akan selesai sekolah.

\section{Saran}

Melihat peserta didik yang membolos di sekolah dengan berbagai faktor yang ada, maka di harapkan :

1. Hendaknya guru BK memberikan perhatian yang lebih kepada peserta didik yang sering membolos sekolah. 2. Hendaknya guru BK mampu berkomunikasi secara intensif terhadap peserta didik yang sering membolos sekolah, agar peserta didik bisa bisa mendapatkan penguatan dan semangat untuk pergi sekolah. 2. Hendaknya guru BK mampu membantu peserta didik yang motivasi masuk sekolahnya rendah di sekolah dengan mencarikan bantuan untuk membuat mereka kembali semangat sekolah.

3. Hendaknya guru BK bisa melakukan HOME VISIT kepada peserta didik yang membolos dengan menemui satu persatu orangtua peserta didik yang membolos membicarakan terkait anaknya yang membolos. 4. Hendaknya kepala sekolah mampu memberikan ketegasan terhadap masalah perilaku membolos peserta didiknya. Karena kebanyakan masalah membolos ini jika dibiarkan akan membuat prestasi peserta didik akan menurun sehingga akan membuat mereka bisa tidak naik kelas atau tidak lulus sekolah.

\section{DAFTAR RUJUKAN}

Arikunto, S. (2014)(). Prosedur Penelitian Suatu Pendekatan Praktik. Jakarta: Renika Cipta

Amaliyah. (2018). Layanan Konseling Kelompok Dengan Teknik Self Management Untuk Mengurangi
Perilaku Siswa Membolos Di Smpn 29 Banjarmasin. Jurnal Mahasiswa BK An-Nur : Berbeda, Bermakna, Mulia. Volume 4 Nomor 1. ISSN. 2460-9722.

Baharudin, dan Esa Nur Wahyuni. (2015). Teori Belajar dan Pembelajaran. Yogyakarta: Ar-ruz Media

Ervi,Neni Arni Yeti.2012. Upaya Mengurangi Kebiasaan Buruk Dalam Membolos Dan Mencontek Dengan Layanan Bimbingan Kelompok Siswa. Semarang. (JurnalI lmiah Pendidikan BK)

Gunarsa. (2015). Psikologi untuk membimbing : PT. Gurang Mulia

Gazda, G.M. (1984). Group Counseling A Development Approach. Boston: Allyn and Bacon.

Hammond, Linda-Darling. Austin, Dkk. (2001). How People Learn: Introduction To Learning Theories. Stanford University School of Education.

Haryianto. (2019). Mengatasi Perilaku Membolos Melalui Konseling Individual Dengan Pendekatan Behavior Teknik Selfmanagement Pada Siswa Kelas Xii Tsm Smk Pgri 1 Pogalan Trenggalek. Vol. 3 No. 1

Hintzman, Douglas L. (1978). The Psychology of Human Learning. New York: Harper \& Row, Publishers.

Jihad, Asep dan Abdul Harris. (2009). Evaluasi Pembelajaran Yogyakarta : Pressindo

Kanga, Benjamin Mugambi.(2015). Factors Contributing to Truancy in Secondary Schools in Meru South District Kenya.Journal of Scientific and Research Publications.Vol:5 No.1 
Mahmud. (2011) . Metode penelitian Pendidikan. Bandung : Pustaka Setia.
Maolani, A, Rukaesih dan Cahyana Ucu. (2015). Metodologi Penelitian Pendidikan. Jakarta: Rajawali Pers 